\title{
Confronting Vision 20:2020 Challenges: The Place of Environmental Education in Universal Basic Science
}

\author{
Arowolo, Jacob Gbemiga \\ Integrated Science Department, \\ Federal College of Education, Kontagora, Niger State, Nigeria. \\ Musa, Binta \\ Chemistry Department, \\ Federal College of Education, Kontagora, Niger State, Nigeria.
}

\section{Doi:10.5901/mjss.2013.v4n16p119}

\section{Abstract}

Survival of living organisms on earth cannot be guaranteed without redressing the present devastating environment. Active involvement of all and sundry is highly necessary to manage the present intensive exploitative demands on the environmental resources by organisms. This was why a survey of the place of environmental education in Universal Basic Science for confronting vision 20:2020 challenges from the North central zone of Nigeria was examined in this paper. 536 students randomly selected from 10 Junior Secondary Schools in 4 randomly selected states from the zone participated. Two research hypotheses were tested through t-test analysis of Environmental Challenges Achievement Test (ECAT) scores. The results revealed that there were significant differences in students' achievement on the inclusion of environmental concepts in the students' knowledge of environmental management as well as the contributions of environmental education in resolving vision 20: 2020 environmental challenges. It was recommended among others that every child of school age should be involved in tree planting and cover cropping in all their localities every year; and the need for collaboration between government and farmers in a way that farmers would be helped directly to adopt new techniques and sustainable farming practices in addition to regulated grazing of animals.

Keywords: Vision 20:2020, Resources, Environmental management, Challenges, Basic science.

\section{Introduction}

Nature endows the human species with abundant resources for survival. Man in effect interacts with the natural gifts in order to harness the benefits therein. This interaction has however resulted into imbalance within the ecosystem and has been manifested in series of environmental problems. The signal on environmental degradation had long been noticed in the 1960s when public concerns about the health and environmental hazards of pesticides and other toxic chemicals used by industries were raised (Encarta, 2008). Furthermore, it was recorded that several catastrophic events that followed the use of the chemicals necessitated California to focus attention on the need for environmental conservation that culminated into the first National Earth Day of April 22, 1970, a day recognizing environmental concerns in the United States. Since then concerted efforts had been made on proper environmental management, prominent was that by the United Nations Environmental Programme of 1972 which was formed to encourage international cooperation in conservation and development strategies. Collaboration on environmental conservation issues included the 1987 Montreal Protocol to protect the ozone layer, and the 1992 United Nations Conference on 
Environment and Development (UNCED) in Rio de Janeiro, Brazil.

Like any other countries of the world, Nigeria is faced with series of environmental problems such as: pollution, oil spillage, desertification, flooding, erosion, sand dunes, land slides, storm, and waste disposal among others. Some factors identified by Ogunbiyi (2007) as responsible for the various environmental problems confronting Nigeria include:

a. low level of awareness about the consequences of people's actions on the environment,

b. the poverty level of the people, and

c. the adoption of non-sustainable modes of development.

Findings from the report of Alao (2008) on building Nigerians response to climate change, reveal that "the problem of the environment sticks like a sore thumb at the G8 submit in Japan, raising questions of commitment to promises of reducing poverty in vulnerable regions of the world". Environmental disasters have of recent become a common coin to the entire world and not to the G8 alone. There is every convincing evidences that the world is under serious threat from the environment. But analysts had posited that the environment was only compelled to respond to the abuses mounded on it by human activities. This has created a great concern for world leaders, which is why the issue of environment ran too close to call with matters of economy and poverty at the G8 submit (Alao, 2008). Since the world leaders had been accused of paying lip service to the problem of global warming, they therefore put the issue of environment as one of the important Agenda and promising to set a target of cutting carbon emissions by $50 \%$ by the year 2050 . As observed by Ashworth (2008), the world is changing fast this time because climate change and unregulated irrigation projects are becoming major drivers for redrawing maps. He maintains that "we can literally see environmental disasters unfolding before our eyes; we have a real fear that, in the near future, famous geographical features will disappear forever". It will not be out of sense to agree that environmental disasters pose problems to the health of both the living and those who are yet to be borne. It is therefore necessary to inculcate the skills of developing and maintaining a healthy environment into everyone. This among other necessities as opined by Ake (2001) called for the articulation of vision 20:2020 policy by the Obasanjo administration (1999-2007). By 2009, the Nigeria Vision 20:2020-Economic Transformation Blueprint that could make Nigeria one of the 20 largest economies in the world by 2020 was released as directed by the Yar'adua administration (Igbuzor, 2009). The blueprint stipulates a 10 year plan for stimulating Nigeria's economic growth. It involved the analysis of 29 thematic areas of which a dimension of environmental consciousness and sustainable management rank paramount. To realize the vision, a need to immediately address the most debilitating constraints to Nigeria's growth and competitiveness was noted as a means for creating the platform for success. In spite of the documented dividends of the vision, there are serious defects with respect to environmental management that made it difficult for the attainment of the goal of the vision to be realized. For instance, the vision's strategy did not take into consideration the means through which the poverty level of the people could be tackled, and there was no laid down procedure to attack corruption in the vision with respect to comprehensiveness, consistency, publicity, non-partisanship, and the like (Eleri, 2009).

\section{The Problem}

This study was conducted to examine the place of environmental education in Basic Science as a means for confronting vision 20:2020 environmental challenges. The study specifically tested the following hypotheses:

1. There is no significant mean difference in the inclusion of environmental education in Basic Science on students' knowledge of environmental management.

2. Environmental education in Basic Science has no significant contribution on resolving vision 20:2020 environmental challenges. 


\section{Methodology}

The study adopted a survey design. The entire Junior Secondary School Students I and III in the North central states of Nigeria constituted the population. It was assumed that they have been exposed to topics related to their environment in Basic science but with different levels of coverage. Four out of the six states in this zone were selected by balloting [Benue, (Bn); Kwara, (Kw); Nasarawa, (Na) and Niger, (Ng)]. A school from any three local government headquarters in each of the states selected was purposively selected to ease accessibility. The 12 schools selected were randomly assigned into 6 intact JSS 1 and 6 intact JSS III classes. A sample of 545 participated in the study. Students' teachers on teaching practice from these states assisted in the distribution and retrieval of the instrument used for gathering data in this study.

The instrument used for this study was a 20 -item objective questions tagged Environmental Challenges Achievement Test (ECAT). It was made up of two parts. Part 1 required student's school and class, while the second part contained 20 objective questions with options A-E. The draft was extracted from past National Examinations Council (NECO) Junior School Certificate Examination papers. It was assumed that the questions had undergone standardization by the examination body and as such was taken to be valid and reliable for the study.

\section{Data Analysis}

Only 536 copies out of the 545 copies of the question papers administered could be gathered after the response. The responses were sorted out based on level for hypothesis 1 to be addressed and then on combined states level to address hypothesis 2. The t-test computation of the scores was carried out as indicated in tables 1 and 2 as follows:

Table 1: T-Test Analysis on Students Knowledge of Environmental Management

\begin{tabular}{cccccccc}
\hline Respondents & N & $\overline{\boldsymbol{X}}$ & SD & df & Tcal & Tcrit & P \\
\hline JS I & 283 & 42.5 & 3.2 & & & & \\
JS III & 253 & 63.6 & 4.7 & 532 & 3.257 & 1.96 & $0.015^{*}$ \\
\hline
\end{tabular}

*Significant at .05 alpha level.

Table 2: T-Test Analysis on the Contributions of Environmental Education in Resolving Vision 20:2020 Environmental Challenges

\begin{tabular}{lccccccc}
\hline Respondents & N & $\overline{\boldsymbol{X}}$ & SD & df & Tcal & Tcrit P & \\
\hline Bn \& Ng & 275 & 62.38 & 11.17 & & & & \\
Kw \& Na & 261 & 83.09 & 95.02 & 532 & 3.465 & 1.96 & $0.002^{*}$ \\
\hline
\end{tabular}

*Significant at .05 alpha level.

\section{Discussion}

Hypothesis 1: There is no significant mean difference on the inclusion of environmental concepts in Basic Science on students' knowledge of environmental management.

The result in table 1 reveals that there was a significant mean difference on the inclusion of environmental concepts in Basic Science on students knowledge about environmental management (t-cal = $3.257>$ t-crit $=1.96$; at $p<.05$ ). The hypothesis was therefore rejected as a result. The level of awareness and exposure of students to environmental knowledge reflected the true picture of what they could score from the achievement test on environmental issues. This was while there was a significant mean difference between JS I and JS III students' achievement. This further shows that the greatest changes in the environment and the effects have been learned by JS III students and environmental mismanagement had 
been recognized by them as a threat to human survival. This finding corroborated the view of Graffits (2004) that value clarification strategies develop people's cognitive, affective and psychomotor domains. In the same vein, Superka (2003) had discovered that academic ability had significant effects on people's knowledge of environmental concepts and their attitudes to the environment. It is clear therefore that the inclusion of environmental concepts in Basic Science has improved students' mind set in active participation in the process of tackling the environmental problems due to man-made or climate change. The more the students were exposed to environmental concepts, the more they become aware that the indiscriminate degradation of the environment and over-dependence on agrochemicals as well as pollution were due to poverty that has eaten deep into the nerves of every Nigerian. In view of this, tackling poverty among Nigerians is nonnegotiable and it ought to find a place in Vision 20:2020 if there is genuine intention for the realization of the objectives of the Vision. Although environmental degradation may be natural or man-made, it was endowed of man to prevent and control it. This is clear evidence here that the inclusion of concepts about the control of environmental degradation in Basic science will prepare the students for proper management of the environment and may cause them to unconsciously educate other members of their communities. From the foregoing, the nature of environmental stimuli confronting a given area of the country determines the people's reactions. In effect, to address the environmental issues in vision 20:2020, this study has found that the people need a 'psychological restoration' that can acquaint them with up-to-date information on the positive knowledge about environmental management as contained in Basic Science.

Hypothesis 2: Environmental education in Basic Science has no significant contribution for resolving vision 20:2020 environmental challenges.

Table 2 reveals that there was a significant contribution of environmental education in Basic Science for resolving vision 20: 2020 environmental challenges in the North central of Nigeria (t-cal $=3.465>t$-crit $=$ 1.96; at $P<.05)$. This necessitated the rejection of the hypothesis. The results here lay high credence on the means through which environmental education in Basic Science can help resolve environmental challenges in vision 20:2020. It has been recorded that one of the defects of the strategies of the vision is poor implementation (Adejuwon, 2009). Damage inflicted through poor implementation of the vision's policy can be extremely detrimental to the health and economic value of the grasses and soil (Nolte and Dykzeul, 2002).

Now that Nigeria as a whole is more vulnerable to the impacts of environmental conflicts in a way that it has included 'shifts' in the boundaries of major ecological zones, it is expedient to inculcate the tenet of proper environmental management in the students for a span of many years without truncation. Unfortunately, the vision did not include teachers among the experts that formulated the strategy and worst still, the strategy did not receive a wide spread notification (Igbuzor, 2009). In order to confront the challenges ahead with reference to: alteration in animal and plant compositions, greater soil erosion and flooding in areas of higher rainfall, heightened drought and desertification in the northern regions, accelerated sea level rise, salt water intrusion along the coastal belt and man-made oil spillage causing havocs to aquatic life, teachers ought to be duly represented. This is because teachers who are on the field have situation knowledge the happenings in the environment, and such occupy better position to contribute realizable objectives. Observations showed that in the North central zone, the type and extent of damage inflicted by a few selected animal species such as the cattle and sheep feeding on the vascular tissue of grasses in stand of up to six months (especially when there was rain) was in the form of removing the shoot with their incisors. Any grass however is vulnerable, in addition to cattle occasionally trampling the entire grass. Damage on the grassland can be extensive with a single herd and flock of foraging cattle and sheep covering several acres per day. The severity of grass and soil nutrient loss is compounded when the herdsmen set the grasses ablaze in a selfish intent of inducing the sprouting of fresh grasses to feed their herds/flocks. Other negative impacts on environmental resources and infrastructural developments include: indiscriminate refuse disposal, wind erosion, heighten environmental heat (warming), as well as desert encroachment, which are aftermath of human activities. The primary worst threat and substantial damage occurs through cutting of the few scattered trees for timber or conversion to charcoal through crude destructive distillation (a reciprocal 
compliment to poverty). Similarly, burning or grazing of grassland, reduction of old growth trees to supply fuel wood for domestics have been made the villagers to become the primary force of landscape degradation. Also, increased hunting pressure causes declination of the populations of large mammal fauna and flora. Restoration/re-grassing efforts become difficult or impossible since human occupants of this zone add to environmental damage from their daily activities. The indiscriminate tillage of land and unregulated use of agrochemicals aggravates environmental pollution and prompted sudden climatic challenges. These challenges can be resolved as informed by this study if the students were not denied the basic requirements to acquire basic education. This is where Government policy implementation has to receive a genuine turn around.

Based on these findings, the researcher believes that it is expedient that vision 20:2020 involves everyone on the crusade on environmental management by venturing into non-market amenity services. These services are the outputs or benefits of grassland which cannot be bought and sold in a traditional market. Such services include: clearing the air, preserving the natural environment, preventing erosion, preserving biodiversity, reducing the threat of climate change, and providing erosion control services. The ability to preserve the output of the non-market amenity services depends on policies intended to preserve grassland and grassland amenities. In all, the economic impact caused by the animal species and the humans is a function of the current damage plus future loses with the cost associated with replacement. For burnt or trampled grasses and cut trees, the loss is accounted for by estimating the time required to reestablish the tree and the grasses to cover the soil. Thus in time, the resource loss is the monetary value anticipated at the time of soil usage plus the monetary value for protection up to the damage, and the timeintegrated costs associated with reestablishment of future natural resources.

In the public interest, Vision 20:2020 will do well if there is a forum for grass service to assess the nation's public and private renewable resources and develop a national renewable resource programme that will include: a thorough analysis of environmental and economic impacts, coordination of multiple-use and sustained-yield, and public participation. The role of grass service could be such that have the responsibility and opportunity to assure a national natural resource conservation posture that will meet the citizens' needs in perpetuity. The knowledge derived from coordinated public and private learning by students will promote a sound technical and ecological base for the effective management, use and protection of the nation's environment. This is assured because these students are developing into the future. (ie, 2020 and beyond).

The negative impacts of human and other animal species on grassland resources can be extensive. Although damage is most often considered in terms of reduced productivity or delayed harvest cycles, attempts to replace trees or grasses after a harvest or a fire outbreak can also be complete failures because of foraging livestock. The full impact of the animals on grassland resources is frequently difficult to assess because of the complexity of the resources. This provides some insight into the economic and environmental consequences of animal species damage to grassland resources. The temporal and spatial scales of grassland ensure varied habitats, and animal species change with the habitat. Therefore, whether calculating potential damage losses or figuring costs to implement preventive measures to protect grassland resources the estimates must be based on the current state of the grassland, reflecting the species presence which in turn, affect the potential type and the extent of damage and future controls that must be needed as the nature of the resource changes and becomes vulnerable to a new suite of animal species capable of inflicting damage. Exposing students to these challenges in Basic Science will no doubt radiate precautions to adults who indulge in natural resources destruction or exploitation.

\section{Conclusion}

There is a long rope to pull on environmental management for a healthy North central geopolitical zone of Nigeria. For people to rise to the environmental challenges in vision 20: 2020 there is urgent need for conservation, sustainable use and protection of natural resources which include: plants, animals, mineral 
deposits, soils, clean water, clean air and fossil fuels such as coal, petroleum and natural gas. Educators and resource managers spoke of total environmental control and envisioned a discipline that would create a harmonious relationship between man and his environment. In the context of the nation's vision of becoming one of the 20 largest economies in the world by the year 2020, a vibrant and technology enabled activity is crucial.

This is why the learning of environmental concepts in Basic Science is adequate for addressing environmental challenges in the zone. We need greenery to be able to survive, however, environmental degradation and disasters are threatening the green situation in Nigeria, we therefore need to act fast by controlling pollution and reducing causes of devastations that could trigger disasters in our environment by practicing Agriculture that would promote growth in national output, and supports expansion in the industrial sector, enhance foreign exchange earnings, provide food for the teeming population, provide gainful employment, create wealth and reduce poverty on a sustainable basis.

\section{Recommendations}

In spite of the billions of dollars which the Federal government had raked from oil exploration to cater for environmental disasters, there seemed to be no impact. Vision 20: 2020 should be in the position to direct the search-light to some other reliable targets which can help in activating efforts on environmental management and at cutting mismanagement of natural resources in order to reinforce environmental development. For this reason, the following were recommended:

1. There is need to involve every child of school age in tree planting and cover cropping in all their localities every year.

2. There should be collaboration between government and farmers in a way that farmers would be helped directly to adopt new techniques and sustainable farming practices in addition to regulated grazing of animals.

3. Policy to combat desertification incorporated into national sustainable development strategies should be implemented adequately.

4. Policy implementation and consistency on poverty eradication should form a clause and be included in the constitution of the federation.

5. Vision 20: 2020 should reflect a means by which people in collaboration with the government could turn devastated environment into tourist centers as done in Germany.

6. State/stakeholders should identify all lands that require reforestation/re-grassing for treatment.

7. Government should honestly implement Basic Education for all policy to letter.

\section{References}

Adejuwon, S. 2009. The fury of Nation. TELL Magazine, June 29, 2009. 24

Ake, C. 2001. Democracy and Development in Africa. Ibadan: Spectrum Books Ltd.

Alao, F. 2008. Building Nigerians response to climate change (BNRCC) project. TELL Magazine August 11, 2008. 32. 20 22.

Ashwort, M. 2008. Battling a Global Threat. TELL Magazine August 11, 2008. 32. 20-22.

Eleri, E. The fury of Nature. TELL Magazine 29, June 2009. 23.

Graffits, B. 2004. Effects of values clarification and action learning on students environmental problem-solving skills and attitudes. Journal of Environmental value Education. 91:23. University of California.

http://www.nigeriamuse.com/important_documents/?u=inaugural_addresspresident_Umaru_Musa_Yar_adua_of_Nigeria. htm retrieved on 11/04/2013.

Igbuzor, O. 2009. Challenges of Development in Nigeria. Lagos: Robitos Alliance Publishers.

Jibunoh, N. 2008. Fight against desert encroachment (FADE): Africa must act fast. TELL Magazine August 11, 2008. 32. 28-31. 
"Conservation." Microsoft巴 Encarta® 2009 [DVD]. Redmond, WA: Microsoft Corporation, 2008. Retrieved on 02/04/2013.

Nolte, D. L. \& Dykzeul, M. 2002. Wildlife Impacts on Forest Resources. In L. Clark \& J. K. Yoder (eds), Human conflicts with wildlife: economic considerations. Proceedings of the $3^{\text {rd }}$ NWRC special symposium (August 1-3, Fort Collins, Co) National Wildlife Research Center, Fort Collins, Co.

Ogunbiyi, J.O. 2007. Effects of values clarification strategy on in-service teachers' environmental knowledge and attitude in selected secondary schools in Abeokuta, Ogun state. African Journal of Education Research, June/December 2007. 11 (1\&2) 10-14.

Superka, D. 2003. Values education for the environment. Dakin University press, Geelong. 64.

URL:http://lib.colostate.edu/research/agric/damageprobs/econimpact.html retrieved on 28/03/2013. 
